Article

\title{
Sol-Gel and Electrospinning Synthesis of Lithium Niobate-Silica Nanofibers
}

\author{
Jesús Alberto Garibay-Alvarado ${ }^{1}$, Rurik Farías ${ }^{2}$ and Simón Yobanny Reyes-López ${ }^{1, *(D)}$ \\ 1 Instituto de Ciencias Biomédicas, Universidad Autónoma de Ciudad Juárez, Ciudad Juárez 32315, Mexico; \\ al171764@alumnos.uacj.mx \\ 2 Instituto de Ingeniería y Tecnología, Universidad Autónoma de Ciudad Juárez, Ciudad Juárez 32310, \\ Mexico; rurik.farias@uacj.mx \\ * Correspondence: simon.reyes@uacj.mx; Tel.: +52-656-688-2100 (ext. 5124)
}

Received: 17 January 2019; Accepted: 12 February 2019; Published: 26 March 2019

check for updates

\begin{abstract}
Lithium niobate-silica fibers were produced by the combination of the sol-gel method and the electrospinning technique. Two sol-gel solutions starting from niobium-lithium ethoxide and tetraethyl orthosilicate were prepared and then mixed with polyvinylpyrrolidone; the solutions were electrospun in a coaxial setup. The obtained lithium niobate-silica polymeric fibers were approximately $760 \mathrm{~nm}$ in diameter. Raman spectroscopy confirmed the composite composition by showing signals corresponding to lithium niobate and silica. Scanning electron microscopy showed coaxial fibers with a diameter of around $330 \mathrm{~nm}$ arranged as a fibrillar membrane at $800{ }^{\circ} \mathrm{C}$. At $1000{ }^{\circ} \mathrm{C}$ the continuous shape of fibers was preserved; the structure is composed of silica and lithium niobate nanoparticles within the fibers. The formation of crystalline lithium niobate and amorphous $\mathrm{SiO}_{2}$ phase was also confirmed by XRD peaks.
\end{abstract}

Keywords: electrospinning; sol-gel; lithium niobite; nanofibers

\section{Introduction}

Lithium niobate $\left(\mathrm{LiNbO}_{3}, \mathrm{LN}\right)$ is an innovative material which has been researched extensively in the last few years due to its physicochemical properties. It has a fusion temperature close to $1200{ }^{\circ} \mathrm{C}$, a Curie temperature of $1206^{\circ} \mathrm{C}$ [1], and a perovskite-type crystalline structure, that is, it is composed of two cations $\mathrm{A}=\mathrm{Li}$ and $\mathrm{B}=\mathrm{Nb}$, and an anion $\mathrm{X}=\mathrm{O}$ [2]. The crystalline organization in perovskites allows the movement of $\mathrm{B}$ cations provoking a polarization of the crystal while enabling high pyroelectric, photo-refractive, ferro-electric, electro-optic, piezo-optic, acusto-optic and foto-voltaic coefficients, and nonlinear electric susceptibilities [3-5]. Some of the methods adopted for the synthesis of lithium niobate include a water-soluble reaction which solves problems such as the use of toxic compounds, but has a long reaction time and limited control of the reaction conditions [6]; Liu et al. [7] used a combustion method to synthesize high purity LN powders, however, while this approach uses a low reaction temperature and zero solvents, the end product applications may be limited because of the morphological and macroscopic characteristics.

Zeng and Tung [8] had a different approach by using the sol-gel method with niobium (V) ethoxide and lithium nitrate as precursors, which is cheaper to achieve and requires a low calcination temperature as well in comparison with an all-alkoxide reaction, however, this synthesis use acetylacetone as a chelant, which is a highly toxic reactant. Wang et al. [9] also used the sol-gel method with dihydrate lithium acetate and niobium chloride as precursors, but the latter is highly reactive and toxic for humans and the environment and requires special handling. Some of the advantages of the sol-gel method are that due to the relative proximity of the mixed components of the gel, inferior temperatures are required for the formation of the ceramic and crystallization. 
Furthermore, it yields a high purity and homogeneous product and electrospinning solutions for the obtainment of fibers. The most important factors influencing the sol-gel process and the preparation of ceramic fibers by electrospinning are the type and concentration of precursor [10-13].

Organometallic compounds, such as niobium ethoxide $\left(\mathrm{Nb}\left(\mathrm{OCH}_{2} \mathrm{CH}_{3}\right)_{5}\right)$ and lithium hydroxide $(\mathrm{LiOH})$, have been recently used in the processing route. For instance, acid catalysts are necessary, hydrolysis is difficult to control and requires additional steps and a long time for heating, and stirring is needed. In this works is reported that lithium niobate nanofibers were formed by the coalescence of colonies of particles at low temperature, giving rise to nanofibers with two different morphologies, cylindrical and necklace-like nanofibers [14]. The oriented growth in the matrix of the nanofibers is hindered by the fracture of the fibers, so slow heating or treatment at a higher temperature is necessary when using a polymer as a matrix. Recently, there has been an intense research effort on electrospinning of ceramics, we were not able to find many reports on the synthesis of lithium niobate nanofibers by electrospinning. Precursor concentration is a crucial parameter for the efficient preparation of fibers by electrospinning and sol gel because it affects viscosity and surface tension. In the specific case of ceramics, it has been reported that characteristics like diameter, grain growth rate, and sinterability are influenced by concentration values [13]. In this article, the synthesis of $\mathrm{LiNbO}_{3}$ and $\mathrm{SiO}_{2}$ were carried out using the sol-gel method by avoiding the use of harmful reactants while keeping the synthesis as brief as possible.

\section{Materials and Methods}

Lithium niobate sol-gel was prepared by dissolving Lithium-niobium ethoxide (Alfa Aesar 99\%) in ethanol and using acetic acid as a catalyzer for hydrolysis, keeping a molar ratio of 1:10:6. Silica sol-gel was prepared by dissolving tetraethyl orthosilicate in ethanol using hydrochloric acid as a catalyzer for hydrolysis, keeping a molar ratio of 1:0.1. Simultaneously, $6 \mathrm{~mL}$ of a $10 \%$ Polyvinyl pyrrolidone, PVP (Alfa Aesar $M_{\mathrm{W}}$ 1,300,000) solution were prepared using ethanol (Jalmek 99.5\%) as the solvent. This solution was divided into equal amounts and then added to both sol-gels and homogenized for $1 \mathrm{~h}$. Precursor solutions of 0.003 (M003), 0.03 (M03) and $0.05 \mathrm{M}$ (M05) of $\mathrm{LiNbO}_{3}$, and $10 \mathrm{w} / \mathrm{w} \% \mathrm{SiO}_{2}$ were obtained. The precursor solutions were transferred to $10 \mathrm{~mL}$ glass syringes connected through a hose to a coaxial nozzle and placed in a KD Scientific injection pump. The distance used between the nozzle and the collector was $10 \mathrm{~cm}$. The feeding rate was $4 \mathrm{~mL} / \mathrm{h}$ for the outer solution of $\mathrm{SiO}_{2}$ and $3 \mathrm{~mL} / \mathrm{h}$ for the inner solution of $\mathrm{LiNbO}_{3}$, for samples $\mathrm{M} 003$ and $\mathrm{M} 03$; for the sample M05 $1.5 \mathrm{~mL} / \mathrm{h}$ for $\mathrm{SiO}_{2}$ and $3 \mathrm{~mL} / \mathrm{h}$ for the $\mathrm{LiNbO}_{3}$ solution at 9 to $10 \mathrm{kV}$. Fibers were collected on a rotating drum covered with aluminum foil. Characterization of as-spun fibers was carried out by Fourier Transformed Infrared Spectroscopy (ALPHA Platinum, Bruker, Mexico City, Mexico) with 40 scans and a resolution of $4 \mathrm{~cm}^{-1}$ Morphology and diameters were determined by Scanning Electron Microscopy (JSM-6010 PLUS/LA, JEOL, Mexico City, Mexico). Before observation, the membrane samples were coated with gold using a sputter coating. Thermogravimetric Analysis, Differential Thermal Analysis and Differential Scanning Calorimetry were carried out simultaneously with an SDT Q600 instrument (SDT Q600 V20.9 build 20, TA Instruments, Mexico City, Mexico) using a $10^{\circ} \mathrm{C} / \mathrm{min}$ heating rate. The samples treated at $800{ }^{\circ} \mathrm{C}, 1000{ }^{\circ} \mathrm{C}, 1200{ }^{\circ} \mathrm{C}$ and $1400{ }^{\circ} \mathrm{C}$ were characterized by FTIR (ALPHA Platinum, Bruker, Mexico City, Mexico), SEM (JSM-6010 PLUS/LA, JEOL, Mexico City, Mexico), Raman spectroscopy (Alpha 300, Witec, Ulm, Germany) using a $532 \mathrm{~nm}$ laser scanning an area of $5 \mu \mathrm{m}$, and crystalline phases were identified by XRD with parameters $\mathrm{Cu} K \alpha 1,35 \mathrm{kV}, 25 \mathrm{~mA}$ ( $X^{\prime}$ Pert PRO, Malvern Panalytical, Mexico City, Mexico) and a scanning range from $20^{\circ}$ to $40^{\circ}$ at a $2^{\circ} /$ min scan speed.

\section{Results and Discussions}

The SEM images obtained from as-spun samples M003, M03 and M05 are observed in Figure 1. Figure 1a,b show micrographs at 2000 and 50,000 $\times$ of the M003 sample obtained, the fibers were cylindric with a homogeneous surface and random orientation. The average diameter of fibers was 
$760 \pm 82 \mathrm{~nm}$. Figure 1c,d show micrographs at 5000 and 40,000 $\times$ of the M003 sample in which images shows the same morphology with an average diameter of $510 \pm 94 \mathrm{~nm}$. The fibers present a diameter of $330 \pm 83 \mathrm{~nm}$ distributed randomly. A further reduction in the inner flow to $1.5 \mathrm{~mL} / \mathrm{h}$ to produce fibers with a cylindric morphology and homogeneous surface and an average diameter of $330 \pm 118 \mathrm{~nm}$ is shown in Figure 1e,f micrographs at 1200 and 30,000× of the M05 sample. A few defects of round and elongated shape are observed with small accumulations. It is seen that at a low concentration of lithium niobate the fibers appear to be polymer only because the precursor solution of sample M003 is mostly silica sol-gel. The sample M03 presents ruptures and discontinuity in the fibers. On the other hand, by increasing the concentration of lithium niobate, continuity is restored due to the greater stability of the injected flows as a result of the increase in lithium concentration.

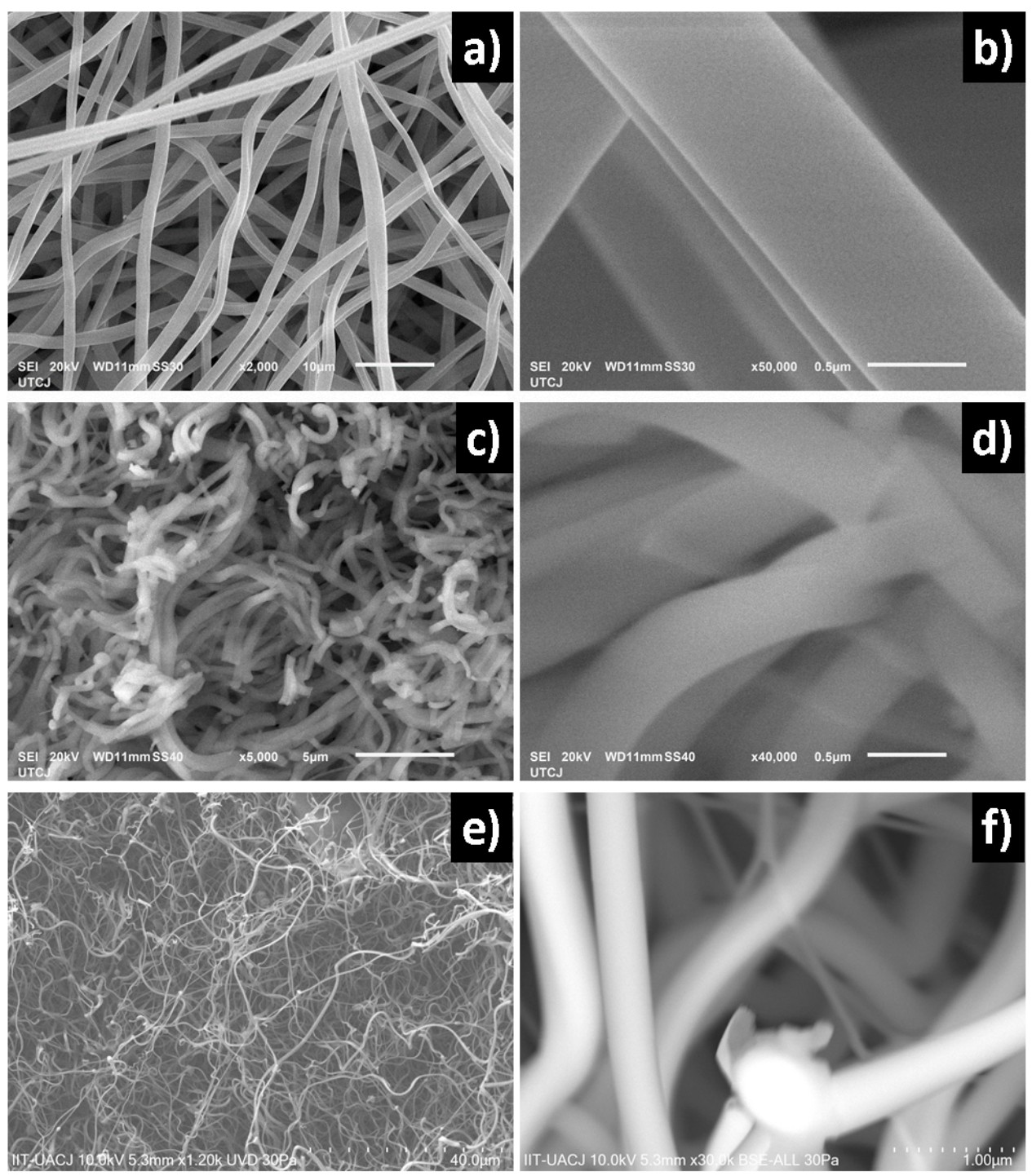

Figure 1. The SEM micrographs of $\mathrm{LiNbO}_{3} / \mathrm{SiO}_{2}$ coaxial fibers samples at $100{ }^{\circ} \mathrm{C}$ : $\mathrm{M} 003$ (a) $2000 \times$ and (b) 50,000 $\times$; M03 (c) 5000 $\times$ and (d) 40,000 $\times$; and M05 (e) $1200 \times$ and (f) $30,000 \times$.

The sample obtained from solution M05 was characterized by DTA, IR, Raman and XRD because this precursor solution allowed for a better electrospun process and gives uniform fibers. Figure 2 is the thermogram by differential scanning calorimetry and thermogravimetric analysis for sample M05, where a loss of $8.07 \%$ weight at $91^{\circ} \mathrm{C}$ can be observed, corresponding to the loss of water. Subsequently, the weight remains stable up to $288^{\circ} \mathrm{C}$ where it descends by $11.59 \%$ corresponding to the organic components derived from the polymer. At $352{ }^{\circ} \mathrm{C}$, the weight loss increases to $17.07 \%$, temperature at 
which a change in crystalline phase occurs and from this point and up to $454{ }^{\circ} \mathrm{C}$ the amount of weight is reduced by $52.4 \%$ due to a great loss of organic matter. At 773 and $917^{\circ} \mathrm{C}$, a loss of $15.97 \%$ and $0.98 \%$ occur, respectively. The analysis reveals that after heat treatment under a temperature of $920{ }^{\circ} \mathrm{C}$, the composite loses up to $86.42 \%$ of its weight.

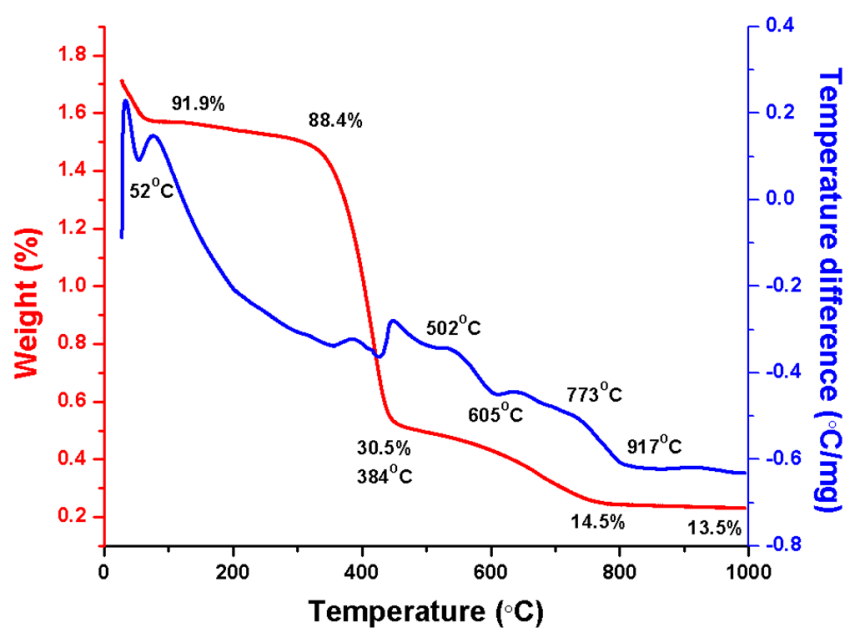

Figure 2. The thermogram of the $\mathrm{LiNbO}_{3} / \mathrm{SiO}_{2}$ coaxial fibers.

The infrared spectrum of as-spun fibers M05 is shown in Figure 3. At $25{ }^{\circ} \mathrm{C}$ the spectra show absorption bands related to functional groups in the PVP, silica and lithium-niobium ethoxide/ethanol/acetic acid solution produced by sol-gel. PVP vibration bands can be observed, a hydroxyl stretching band of $\mathrm{H}_{2} \mathrm{O}$ is present at $3420 \mathrm{~cm}^{-1}$, followed by $\mathrm{C}-\mathrm{H}$ stretching bands at 2900, 1650 and $1410 \mathrm{~cm}^{-1}$. In the fingerprint zone, the stretching of carbonyl $(\mathrm{C}=\mathrm{O})$ bonds can be observed at $1655 \mathrm{~cm}^{-1}$, while scissoring bands of methyl groups are present at 1441,1415 and $1379 \mathrm{~cm}^{-1}$ and other the characteristic vibration of the $\mathrm{C}=\mathrm{O}$ group appears at 1291 and $650 \mathrm{~cm}^{-1}$ to the nitrogen of the tertiary amine in PVP, C-O bands at $1000-1050 \mathrm{~cm}^{-1}$ and $\mathrm{CH}$ bands a $1400-1500 \mathrm{~cm}^{-1}$ can be observed. A band corresponding to $\mathrm{C}-\mathrm{N}$ bonds is observed at $1291 \mathrm{~cm}^{-1}$ and IR spectra show peaks for the bonds $\mathrm{Nb}-\mathrm{O}$ at $500-700 \mathrm{~cm}^{-1}$. The infrared analysis of the $\mathrm{SiO}_{2}$ fibers (black), $\mathrm{LiNbO}_{3} / \mathrm{SiO}_{2}$ coaxial fibers at $800{ }^{\circ} \mathrm{C}$ (blue), and $1100{ }^{\circ} \mathrm{C}$ (green) and $\mathrm{LiNbO}_{3}$ powders (red) are shown in Figure 2 . The intensity of carbonyl vibration bands decreases at $200^{\circ} \mathrm{C}$, while $\mathrm{C}-\mathrm{H}$ almost disappears. Both phenomena are caused by polymer decomposition at $180^{\circ} \mathrm{C}$. Organic matter is lost completely and characteristic bands of silica appear at $500^{\circ} \mathrm{C}$. Vibration bands of $\mathrm{Si}-\mathrm{O}$ bonds are present as symmetric (1220 and $\left.800 \mathrm{~cm}^{-1}\right)$ and asymmetric $\left(1080 \mathrm{~cm}^{-1}\right)$ stretching, and the scissoring $\left(460 \mathrm{~cm}^{-1}\right)$ modes [12]. Two important changes took place at $800^{\circ} \mathrm{C}$, first, chemical stability is reached by the ceramic fibers, represented by the loss of the $\mathrm{Si}-\mathrm{OH}$ and $\mathrm{M}-\mathrm{OR}$ bonds. Figure 3 shows the vibrations corresponding to $\mathrm{Nb}-\mathrm{O}$ at 900,700 and $550 \mathrm{~cm}^{-1}$ at $800^{\circ} \mathrm{C}$. The peaks become defined as the temperature increases. The spectrum of $\mathrm{LiNbO}_{3} / \mathrm{SiO}_{2}$ coaxial fibers is compared with the crystalline lithium niobate powders.

The coaxial fibers samples M03 and M05 at $800{ }^{\circ} \mathrm{C}$ were characterized by Raman spectroscopy, the continuous structure of the fibers can be observed in the Raman spectroscopy map in Figure 4a,c. Figure $4 \mathrm{~b}$,d show the Raman spectrum corresponding to lithium niobate, showing vibrations of the bond $\mathrm{Nb}-\mathrm{O}$ in the range of $670-550 \mathrm{~cm}^{-1}$, the bond $\mathrm{O}-\mathrm{Nb}-\mathrm{O}$ at $432 \mathrm{~cm}^{-1}$ strongly coupled to the $\mathrm{Li}-\mathrm{O}$ and $\mathrm{O}-\mathrm{Li}-\mathrm{O}$ bonds, while weak signals at $238 \mathrm{~cm}^{-1}$ are assigned to the deformation of $\mathrm{Nb}-\mathrm{O}$. Vibrations corresponding to $\mathrm{SiO}_{2}$ are detected in the outside of the fibers, while vibrations corresponding to $\mathrm{LiNbO}_{3}$ are detected in the inside of the fibers, according to the coaxial configuration. In addition, vibrations were detected at $800,619 \mathrm{~cm}^{-1}$ and from 200 to $559 \mathrm{~cm}^{-1}$, corresponding to the vibrations of the $\mathrm{O}-\mathrm{Si}-\mathrm{O}$ bonds at $810 \mathrm{~cm}^{-1}$. It is noticeable that the higher the concentration of lithium niobate, the greater the definition of the silica edges of the fibers. 


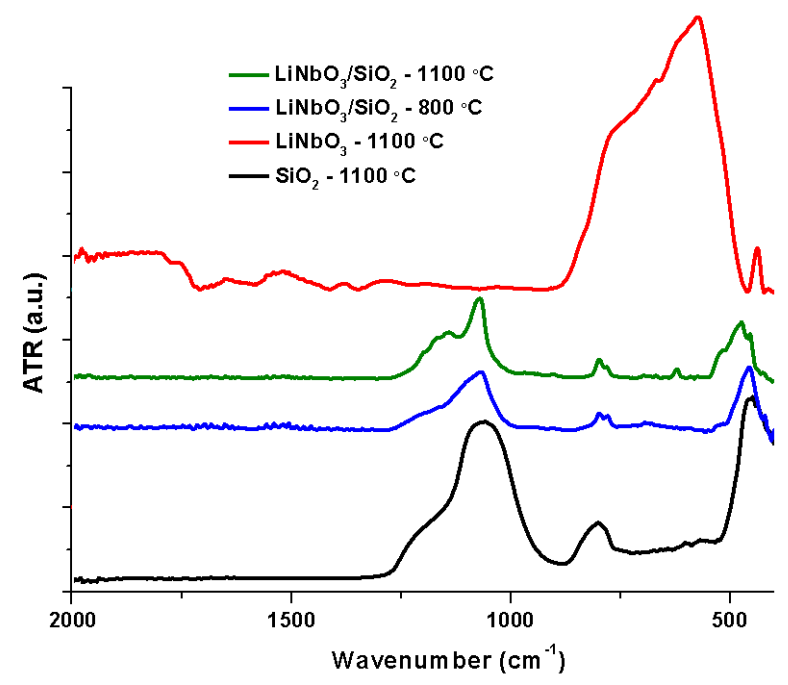

Figure 3. The infrared spectrum of the $\mathrm{LiNbO}_{3} / \mathrm{SiO}_{2}$ coaxial fibers.
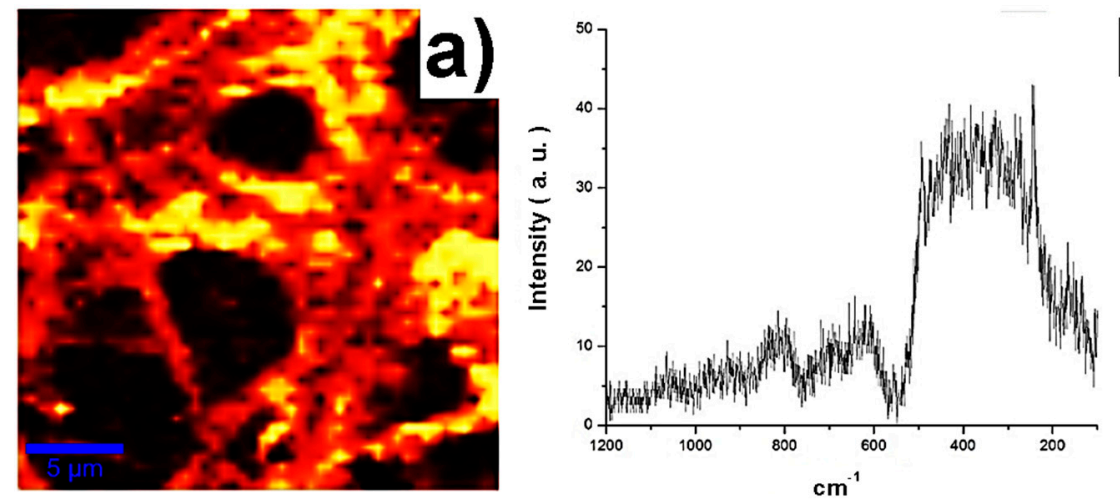

b)
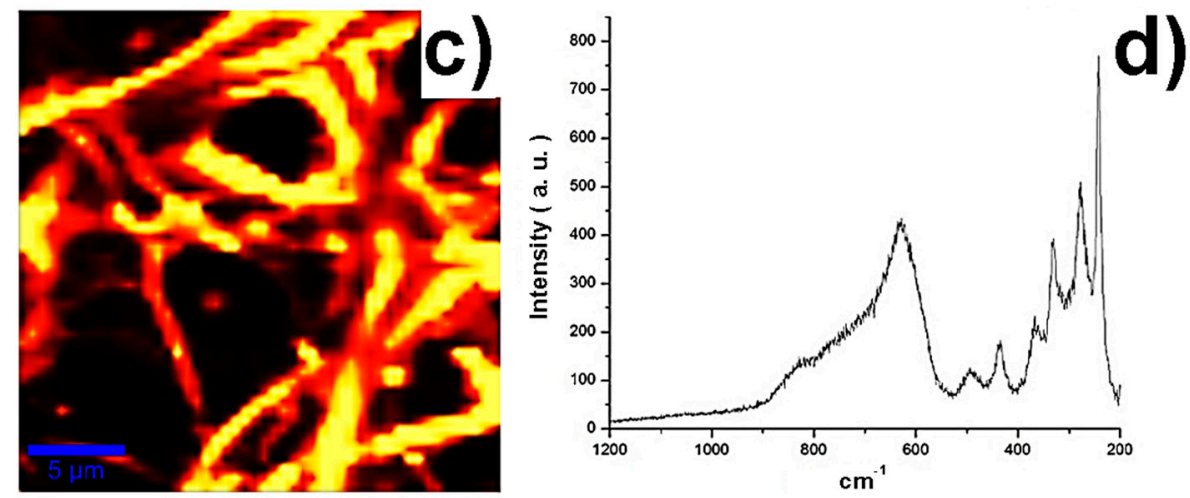

Figure 4. The Raman spectroscopy mapping and Raman spectrum of the $\mathrm{LiNbO}_{3} / \mathrm{SiO}_{2}$ coaxial fibers for samples M03 (subsections (a) and (b)) and M05 (sunsections (c) and (d)) sintered at $800{ }^{\circ} \mathrm{C}$.

Figure 5 shows samples after thermal treatment at $800^{\circ} \mathrm{C}$. As observed in the images, the mean diameters and standard deviation decreased considerably. For instance, the diameter in sample M003 (Figure 5a,b) decreased 47\% (diameter $360 \pm 120 \mathrm{~nm}$ ). Likewise, the sample obtained from solution M03 (Figure 5d,e) decreased 54\% to a mean diameter of $280 \pm 76 \mathrm{~nm}$. As observed in Figure 5f,g, a continuous and smooth surface is retained in sample M05, and the diameter decreases $57 \%$ to $190 \pm 140 \mathrm{~nm}$. As observed in Figure 5, the fibrous continuous morphology was lost in samples prepared, and lithium niobate particles formed due to grain growth and glass formation. However, the original fiber structure is observed in all areas. It was observed that lithium niobate particles increased with the increment in precursor concentration. At low concentrations, only a few crystals are formed. In comparison, the amount of precursor available in more concentrated solutions caused 
the higher center orientation of particles. These processes lead to the formation of coaxial-fibers of wider diameters due to the incorporation of silica. Nanometric particles of lithium niobate inside of fibers were obtained from precursor solutions.
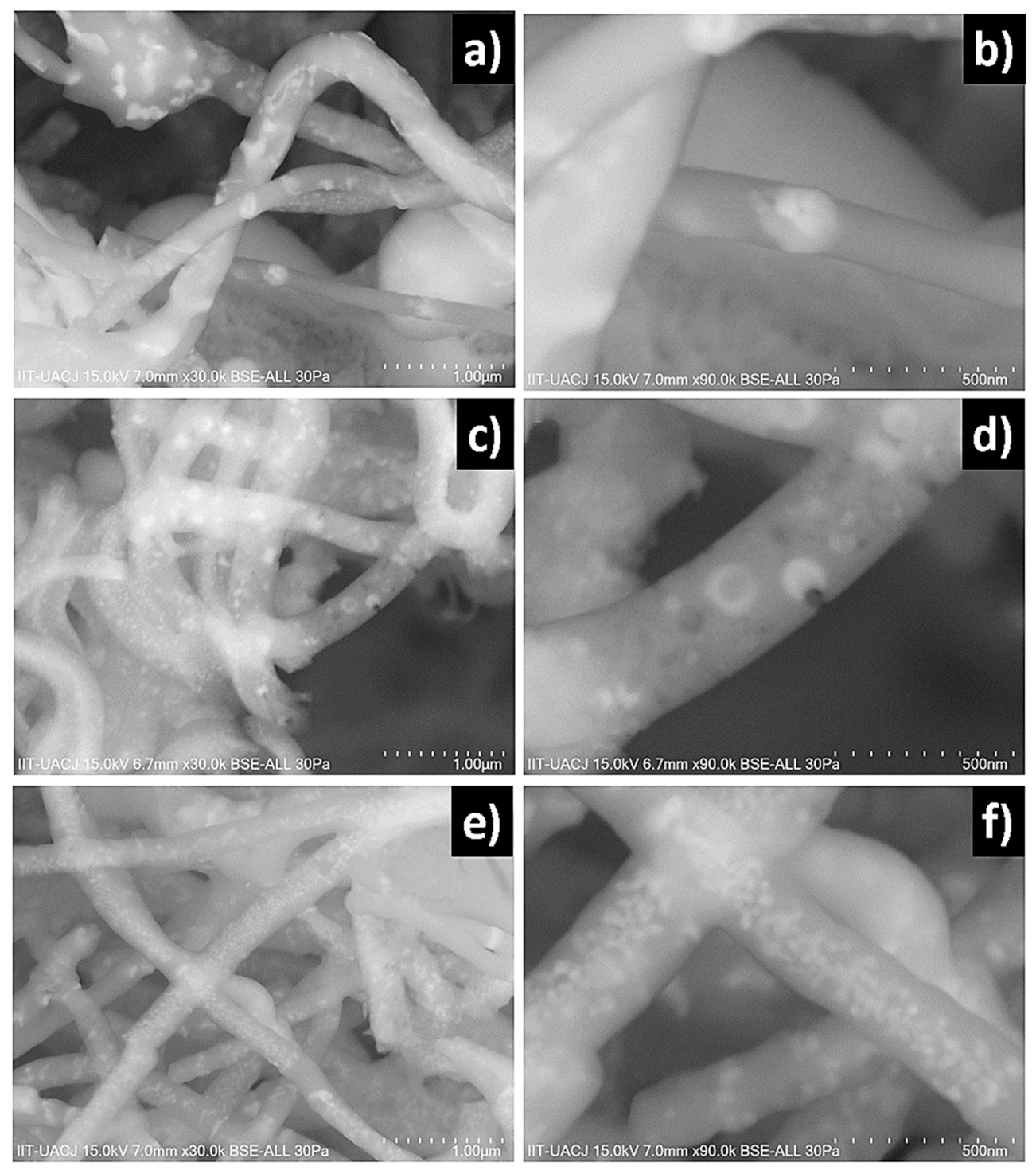

Figure 5. The SEM micrographs of $\mathrm{LiNbO}_{3} / \mathrm{SiO}_{2}$ coaxial fibers for samples M003 (incises (a) and (b)), M03 (incises (c) and (d)) and M05 (incises (e) and (f)) sintered at $800{ }^{\circ} \mathrm{C}$.

Figure 6 shows the SEM micrograph zone obtained from the coaxial fibers M05 at $1000{ }^{\circ} \mathrm{C}$. The fibers were observed with the same morphology of a continuous structure composed of silica with lithium niobate nanoparticles within the fibers. It is noticeable that at a higher temperature the diameter of the fibers increases to $637 \pm 127 \mathrm{~nm}$ due to the fusion of the formed glass and the coalescence of the fibers. In the zoom of the Figure $5 \mathrm{c}$ to $80,000 \times$ lithium niobate particles are clearly seen in white contrast. EDS analysis in Figure $5 \mathrm{c}$ shows that the fibers are composed mainly of $\mathrm{O}$ (61.65 wt \%), Si (20.36 wt \%), C (16.05 wt \%), and $\mathrm{Nb}(1.93 \mathrm{wt} \%)$. The resulting concentration is 0.02 moles for $\mathrm{LiNbO}_{3}$ approximately near to the initial precursor solutions.

To confirm the existence of the lithium niobate nanoparticles within the fibers, an XRD analysis was performed, showed in Figure 7. XRD of $\mathrm{LiNbO}_{3}$ fibers showed the formation of a curve of approximately $20^{\circ}$ to $30^{\circ}$ belonging to silica and crystalline lithium niobite peaks according to the Raman and IR results. In this diffractogram, the habitual fluorescence background was seen due to the 
amorphous $\mathrm{SiO}_{2}$ phase, but also, a Quartz phase was found and characterized by their main diffracted peaks (100), (011) and (110) using JCP: 01-087-2096. The formation of crystalline lithium niobate phase was also confirmed by XRD peaks. Crystallographic indexation was obtained using JCP: 00-074-2238 for trigonal (R3c) indicating (012), (104), and (110) as the principal directions.
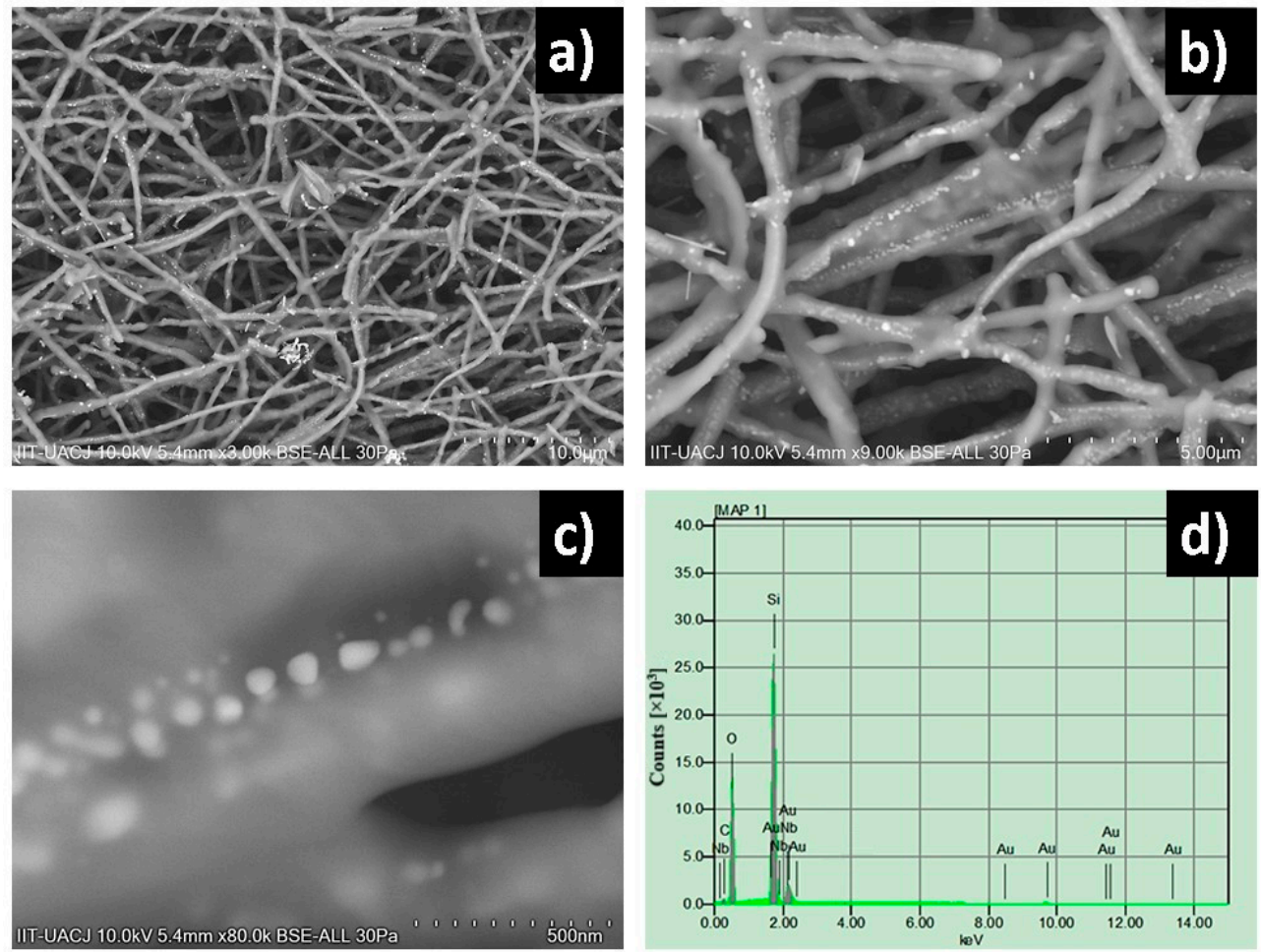

Figure 6. The SEM micrographs of the $\mathrm{LiNbO}_{3} / \mathrm{SiO}_{2}$ coaxial fibers at $1000{ }^{\circ} \mathrm{C}$ : (a) $3000 \times$; (b) $9000 \times$; (c) $80,000 \times$ and (d) EDS.

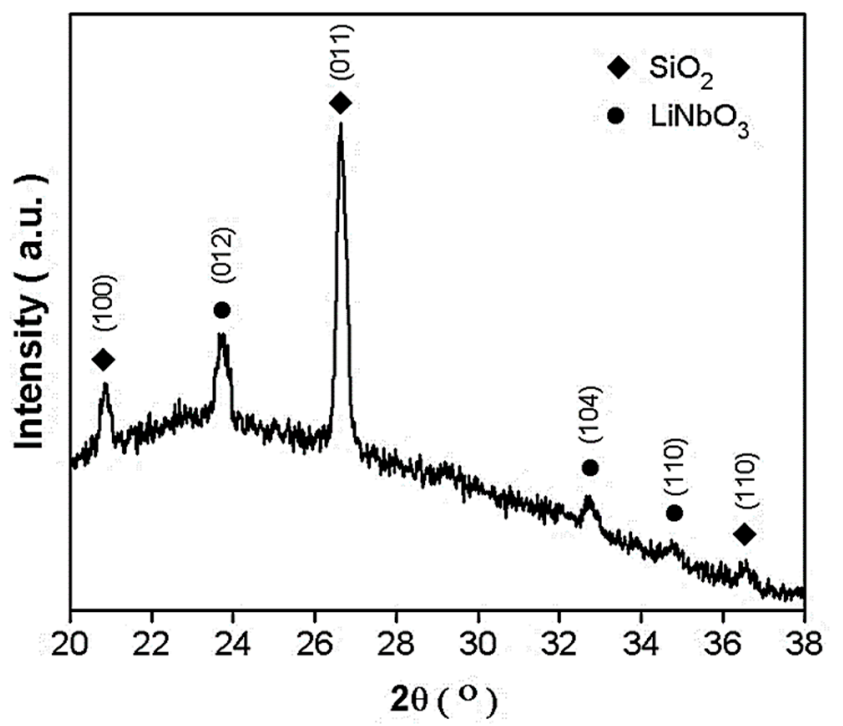

Figure 7. The $\mathrm{XRD}$ of the $\mathrm{LiNbO}_{3} / \mathrm{SiO}_{2}$ coaxial fibers at $1000{ }^{\circ} \mathrm{C}$.

\section{Conclusions}

An alternative methodology was obtained for the synthesis of lithium niobite, which combines the sol-gel and electrospinning technique to produce a fibrillar ceramic composite composed of silica and lithium niobate. Characterization by infrared spectroscopy, Raman spectroscopy, X-ray diffraction 
and scanning electron microscopy showed the formation of ceramic fibers of lithium-silica niobate. The continuous shape of fibers was preserved with the presence of discontinuity of the lithium niobate nucleus found surrounded by silica. It was observed that the concentration of the precursor influences the morphology and stability of the fibers; the use of the silica improves the characteristics of the fibers as well, resulting in continuous fibers. The $\mathrm{LiNbO}_{3} / \mathrm{SiO}_{2}$ coaxial fibers were analyzed by the X-ray diffraction technique and the $\mathrm{XRD}$ of $\mathrm{LiNbO}_{3} / \mathrm{SiO}_{2}$ fibers, showing the formation a curve of approximately $20^{\circ}$ to $30^{\circ}$ belonging to the silica and crystalline lithium niobite peaks according to the SEM, Raman and IR results.

Author Contributions: S.Y.R.-L. and R.F. generated conceptualization; S.Y.R.-L. designed methodology, performed the experimental work, characterized the materials and devices analyzed results, supervised the entire research work; and J.A.G.-A., S.Y.R.-L. and R.F. wrote, reviewed and edited the manuscript.

Funding: This research no received external funding.

Acknowledgments: Thanks to PRODEP, Universidad Autónoma de Ciudad Juárez and CONACYT for supporting this investigation. Reyes-Lopez thanks Carlos Rodriguez for SEM images and Alejandra Peña and Hector Martinez for investigation.

Conflicts of Interest: The authors declare no conflict of interest.

\section{References}

1. Volk, T.; Wöhlecke, M. Lithium Niobate: Defects, Photorefraction and Ferroelectric Switching; Springer Science \& Business Media: Berlin, Germany, 2008.

2. Wong, K.K. Properties of Lithium Niobate; INSPEC: London, UK, 2002.

3. Smith, R.T.; Welsh, F.S. Temperature dependence of the elastic, piezoelectric, and dielectric constants of lithium tantalate and lithium niobate. J. Appl. Phys. 1971, 42, 2219-2230. [CrossRef]

4. Arizmendi, L. Photonic applications of lithium niobate crystals. Phys. Status Solidi A 2004, 201, 253-283. [CrossRef]

5. Cudney, R.S.; Ríos, L.A.; Orozco Arellanes, M.J.; Alonso, F.; Fonseca, J. Fabricación de niobato de litio periódicamente polarizado para óptica no lineal. Revista Mexicana de Física 2002, 48, 548-555.

6. Camargo, E.R.; Kakihana, M. Low temperature synthesis of lithium niobate powders based on water-soluble niobium malato complexes. Solid State Ion. 2002, 151, 413-418. [CrossRef]

7. Liu, M.; Xue, D.; Zhang, S.; Zhu, H.; Wang, J.; Kitamura, K. Chemical synthesis of stoichiometric lithium niobate powders. Mater. Lett. 2005, 59, 1095-1097. [CrossRef]

8. Zeng, H.C.; Tung, S.K. Synthesis of lithium niobate gels using a metal alkoxide-metal nitrate precursor. Chem. Mater. 1996, 8, 2667-2672. [CrossRef]

9. Wang, L.H.; Yuan, D.R.; Duan, X.L.; Wang, X.Q.; Yu, F.P. Synthesis and characterization of fine lithium niobate powders by sol-gel method. Cryst. Res. Technol. 2007, 42, 321-324. [CrossRef]

10. Eichorst, D.J.; Howard, K.E.; Payne, D.A.; Wilson, S.R. Crystal structure of lithium niobium ethoxide (LiNb $\left(\mathrm{OCH}_{2} \mathrm{CH}_{3}\right)_{6}$ : A precursor for lithium niobate ceramics. Inorg. Chem. 1990, 29, 1458-1459. [CrossRef]

11. Garibay-Alvarado, J.A.; Espinosa-Cristóbal, L.F.; Yobanny, S. Fibrous silica-hydroxyapatite composite by electrospinning. Int. J. Res. Granthaalayah 2017, 5, 39-47. [CrossRef]

12. Roque-Ruiz, J.H.; Martínez-Máynez, H.; Zalapa-Garibay, M.A.; Arizmendi-Morquecho, A.; Farias, R.; Reyes-López, S.Y. Surface enhanced Raman spectroscopy in nanofibers mats of $\mathrm{SiO}_{2}-\mathrm{TiO}_{2}-\mathrm{Ag}$. Results Phys. 2017, 7, 2520-2527. [CrossRef]

13. Roque-Ruiz, J.H.; Medellín-Castillo, N.A.; Reyes-López, S.Y. Fabrication of $\alpha$-alumina fibers by sol-gel and electrospinning of aluminum nitrate precursor solutions. Results Phys. 2018, 12, 193-204. [CrossRef]

14. Maldonado-Orozco, M.C.; Ochoa-Lara, M.T.; Sosa-Márquez, J.E.; Olive-Méndez, S.F.; Espinosa-Magaña, F. Synthesis and characterization of electrospun $\mathrm{LiNbO}_{3}$ nanofibers. Ceram. Int. 2015, 41, 14886-14889. [CrossRef] 